\title{
Beneficial Effect of Incorporation of Slag on the Hydration Heat, Mechanical Properties and Durability of Cement Containing Limestone Powder
}

\author{
Toufik Boubekeur ${ }^{1,2,{ }^{*}, \text { Bensaid Boulekbache }}{ }^{2}$, Mohamed Salhi $^{3}$, Karim Ezziane ${ }^{2}$, EL.Hadj Kadri ${ }^{4}$
}

\author{
${ }^{1}$ Ahmed Ben Yahia El Wancharissi University of Tissemsilt, BP 182, 38000, Tissemsilt, Algeria \\ ${ }^{2}$ Hassiba Benbouali University of Chlef, BP 151, 02000, Chlef, Algeria \\ ${ }^{3}$ Ahmed Zabana University of Relizane, BP, 48000 Relizane, Algeria \\ ${ }^{4}$ Laboratory of L2MGC, University of Cergy Pontoise, 95031, French
}

\begin{abstract}
This paper presents the experimental results of a wide research program, tending to determine the hydration mechanism, mechanical properties and the durability performance of ternary cement containing limestone powder and slag. The limestone powder increase the hydration at early ages inducing a high strength at, but it can reduce the later strength due to the dilution effect. On the other hands, Slag (S) contributes to increase the compressive strength at later ages. Hence, at medium blended cement (OPC-LPS) with better performance could be produced. Results show at later age the Slag is very effective in producing ternary blended cements with similar on higher compressive strength than the ordinary Portland cement at 28 and 90 days. For durability, the incorporation of the slag into the cement containing limestone powder improves remarkably resistance to attack by acids and sulfates and it has been found that the durability of the cements never depends on the mechanical strength.
\end{abstract}

\section{Introduction}

Due to the utilization of plenty of cementitious materials in quality concrete, many researchers are interested in studying the influence of mineral additions on the properties of cement.

The presence of sulfate influenced the early-age reaction kinetics of the clinker phases and supplementary cementitious materials. However, even after sulfate depletion, the course of hydration heat and microstructures formed were significantly influenced. Increasing the sulfate level resulted in a gradual increase of the fraction of ettringite over AFm phases, coarser porosity and lower water content of the C-S-H [1].

The acidic attack is a topic of increasing significance, owing to the spread of damage to concrete structures in both urban and industrial.

The addition of limestone powder (LP) increment on water demand improves the cement packing and blocks the capillary pores. Large numbers of studies [2.3.4] have show that slag (S) has been widely used as a cement replacement in ordinary Portland cement because of their advantageous for improving mechanical and durability concrete properties and for bringing environmental and economic benefits.

The limestone powder contributes to the increase strength at early and the slag increase the strength at the long term. The replacement of a part of clinker by slag has led to the improvement of the compressive strength at 28 days, but with a slight decrease at 7 days [5]. On the other hand, the best combination of these minerals additions, can lead to an enhanced durability performance.

An investigation on the influence of slag on formation of thaumasite, ettringite and gypsum in specimens exposed to magnesium sulphate has shown that in specimens with $70 \%$ slag cement and 30\% ordinary Portland cement, it is principally ettringite that forms as sulphate attack product; while in specimen made by slag cement only gypsum is formed and no thaumasite or ettringite are produced [6].

In Algeria most of the cement is being blended with additions such as limestone and slag. Effete of utilizing both LF and GBFS on concrete properties is not well cemented in the literature.

The slag (S), either as a constituent of cements or as a mineral admixture, is widely used to make not only traditional concrete but also high-performance concrete, which has several advantages in terms of workability, long-term strength, and durability [4.7].The hydration heat of slag is initially lower than that of Portland cement. Thereafter, Portland cement containing slag typically shows a reduction of strength at early ages and similar or greater strength at later ages [8]. Rao et al.

\footnotetext{
Corresponding author: t_boubekeur@yahoo.fr
} 
studied the Abrasion resistance and mechanical properties of roller compacted concrete with slag. They also found that abrasion resistance of roller compacted concrete with slag (S) as mineral admixture was strongly influenced by its compressive strength irrespective of slag content [9].

The objective of this of this experimental work is to present the optimization in ternary cement containing limestone powder and the slag of the compressive strength and the durability performance. The degree of hydration of mortar containing ternary blended cement (OPC-LF-S) is also presented in this study was measured, up to 5 days and the mechanism hydration is discussed.

\section{EXPERIMENTAL}

\subsection{Material properties, mortar mixture proportion}

A study was conducted on ordinary Portland cement (OPC), where is replaced by $20 \%$ of limestone powder (LP) and 10, 20 and $30 \%$ of slag (S). The Blaine specific surface for cement and the addition was measured with Blaine method according to NF EN 196-6 [10] and is given in Table 1. The chemical compositions and physical properties of the materials used are summarized in Table1.

Table 1.The chemical compositions and physical properties of the materials used.

\begin{tabular}{|c|c|c|c|}
\hline & $\begin{array}{c}\text { Ordinary } \\
\text { Portland } \\
\text { Cement (OPC) }\end{array}$ & $\begin{array}{c}\text { Limestone } \\
\text { powder } \\
(\text { LP) }\end{array}$ & $\begin{array}{c}\text { Slag } \\
(\mathrm{S})\end{array}$ \\
\hline $\mathrm{SiO}_{2}$ & 20.58 & 0.55 & 42.20 \\
\hline $\mathrm{Al}_{2} \mathrm{O}_{3}$ & 4.90 & 0.40 & 6.85 \\
\hline $\mathrm{Fe}_{2} \mathrm{O}_{3}$ & 4.70 & 0.17 & 1.90 \\
\hline $\mathrm{CaO}$ & 62.8 & 53.47 & 42.20 \\
\hline $\mathrm{MgO}$ & 0.53 & 1.02 & 4.72 \\
\hline $\mathrm{SO}_{3}$ & 2.28 & 1.50 & 1.54 \\
\hline $\mathrm{Na}_{2} \mathrm{O}$ & $/$ & 0.02 & 0.12 \\
\hline $\mathrm{K}_{2} \mathrm{O}$ & $/$ & 0.05 & 0.43 \\
\hline $\begin{array}{c}\text { Loss of } \\
\text { ignition }\end{array}$ & 1.00 & 43.13 & 0.80 \\
\hline $\begin{array}{c}\text { Specific } \\
\text { density }\end{array}$ & 3.1 & 2.7 & 2.9 \\
\hline $\begin{array}{c}\text { Blaine } \\
\text { Finesses cm }\end{array}$ & 3000 & 3200 & 3400 \\
\hline $\begin{array}{c}\text { Glass content, } \\
\text { \% }\end{array}$ & $/$ & & $/$ \\
\hline
\end{tabular}

\subsection{Testing}

The hydration heat is measured by a semi adiabatic calorimeter according to the NF EN 196-9 standard [11]. The method consists of quantifying the heat generated during cement hydration using a thermally insulated bottle. The test is prepared at laboratory temperature of
$20{ }^{\circ} \mathrm{C}$. The measurements are made over $120 \mathrm{~h}$. The total hydration heat is calculated by the following expression (1):

$$
q(t)=\frac{C}{m_{c}} \Delta \theta+\frac{1}{m_{c}} \int_{0}^{t} \alpha \Delta \theta d t
$$

Where:

$\mathrm{C}$ is the total thermal capacity of the mortar filled calorimeter $\left(\mathrm{J} /{ }^{\circ} \mathrm{C}\right), \mathrm{mc}$ is the cement or powder mass $(\mathrm{g})$, $\Delta \mathrm{h}$ is the mortar temperature rise $\left({ }^{\circ} \mathrm{C}\right)$, and a is the total calorimeter thermal loss coefficient $\left(\mathrm{J} / \mathrm{h}{ }^{\circ} \mathrm{C}\right)$.

Five blended cements were formulated by the addition in the cement (OPC), 20\% of limestone powder (LP) and slag, from $0 \%$ to $30 \%$. All replacements were made by mass. Sand/cement ratio is equal to 3 and water/cement ratio is 0.50 . For all mixtures prepared were mixed according to the ASTM C305-06 standard [12].

The strength of mortars was determined in accordance with the European standard EN196-1[13]. The mortar specimens were prepared by casting $40 \mathrm{~mm}$ cubes. After casting, specimens were left covered with a plastic sheet. After removal from the moulds, at $24 \mathrm{~h}$ of age, mortar specimens were immersed in water saturated with lime at $20^{\circ} \mathrm{C}$ until the age of testing at compressive strength $(2,7,28$ and 90 days).

The durability was conducted only on control cement and the cement containing $20 \%$ of limestone powder, $10 \%, 20 \%$ and $30 \%$ of slag. For the sulfate attack tests, the mortars specimens were immersed in 5\% magnesium sulfate $\left(\mathrm{MgSO}_{4}\right)$ at laboratory temperature $20^{\circ} \mathrm{C}$.The sulfate attack was evaluated through the measurement of the expansion on the prismatic specimens measuring $4 \times 4 \times 16 \mathrm{~cm}^{3}$. The relative acid attack was determined in accordance with ASTM C-267[14]. The mortars specimens measuring $4 \times 4 \times 4 \mathrm{~cm}^{3}$, were cured in water at $20^{\circ} \mathrm{C}$ for 28 days before subjected to acid attack. Three specimen of each mortar mix were immersed in 3\% sulfate acid $\left(\mathrm{H}_{2} \mathrm{SO}_{4}\right)$. The solution was renewed every 15 days and the weight loss of the specimens measured. The attacked portions of the mortar specimens were cleaned with deionizer water and then the acid attack was evaluated through measurement of the weight loss of the specimens determined as follows:

$$
\text { Mass loss }(\%)=100(W 2-W 1) / W 1
$$

Where M1 is the weight of the specimen before immersion and M2 is the weight of the cleaned specimen after immersion.

\section{RESULTS AND DISCUSSION}

\subsection{Hydration heat}

The hydration rate of cement based composite mainly depends on three parameters: the cement content, the activity of admixture, and the effect of admixture on the hydration of cement. The results of the hydration heat of 
mortars are illustrates in Fig.1. The cement containing $20 \%$ of limestone powder is characterized by a rapid hydration, which reaches $70 \%$ of its final value at the first day and accomplishes its maximum value $90 \%$ at the third days. The fine particles of limestone powder can act as heterogeneous nucleation site on which the product of $\mathrm{C}-\mathrm{S}-\mathrm{H}$ gel could precipitate, so limestone powder has a promoting effect on the hydration of cement. Barbara et al. [15] found that the exothermic peak in the end of the acceleration period appeared $1 \mathrm{~h}$ head of time and the cumulative heat after $72 \mathrm{~h}$ increased by replacing $4 \%$ of cement with limestone powder. This was because the reduction of cement content was insignificant, but the promoting effect of limestone powder was significant. The addition of limestone powder in the cement can increase the rate of hydration, which induces a decrease in the capillary pores [16].

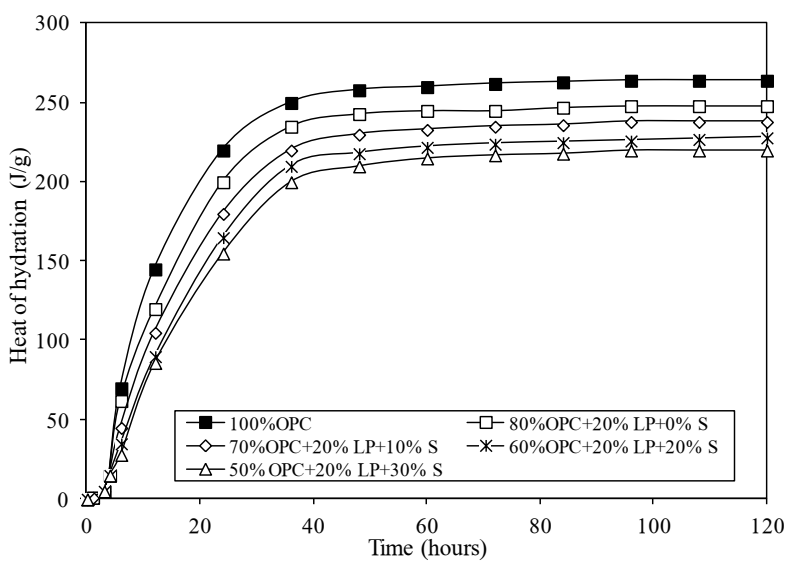

Fig.1. Hydration Heat for Ternary Blended Cement Containing Limestone Powder and Slag at 120 hours.

The incorporation $20 \%$ of LP in ordinary Portland cement decreases the hydration heat to $6 \%$. The hydration heat of ternary binders containing, the slag and limestone powder are shown in Fig.1. It is clear that the hydration heat of cement blended decreases with increases the percentage of blast furnace slag $(80 \% \mathrm{OPC}+20 \% \mathrm{LP}+0 \% \mathrm{~S})$. For example the substitution of 10,20 and $30 \%$ of slag in the cement containing $20 \%$ of limestone powder the hydration heat decreases of the order 11,16 and $20 \%$ respectively; this is due to its latent hydraulic of slag that reacts at later age.

Compared to composite binder containing limestone, lower amount of hydration heat is released for composite binder containing the same amount of slag due to the lower activity of slag. Also, is higher compared by others ternary cements. One can explain these results by the character latent hydraulic of slag that is manifested belatedly. The exothermic peak in the end of the acceleration period of the binder containing LP is higher than that of the ternary cement containing LP and S, and the exothermic peak of the binder containing limestone powder appears earlier. It is obvious that the exothermic rate of the binder containing limestone powder is much faster than that of the binder containing steel slag in the acceleration period. In the deceleration period, their exothermic rates are close to each other [17].

\subsection{Development of the compressive strength}

The results reported in Fig.2 present the evolution of compression strength with age of mortars with ternary binders as a function of mineral additions and their substitution rates. It was noticed from these figures the typical development of compression strength is for ordinary Portland cement, mortars containing $20 \%$ of limestone powder and ternary cement containing $20 \%$ of limestone powder and $10 \%$ of Slag. For ordinary Portland cement the compressive strength à generally is higher than author's types of cement at early ages (7 days).

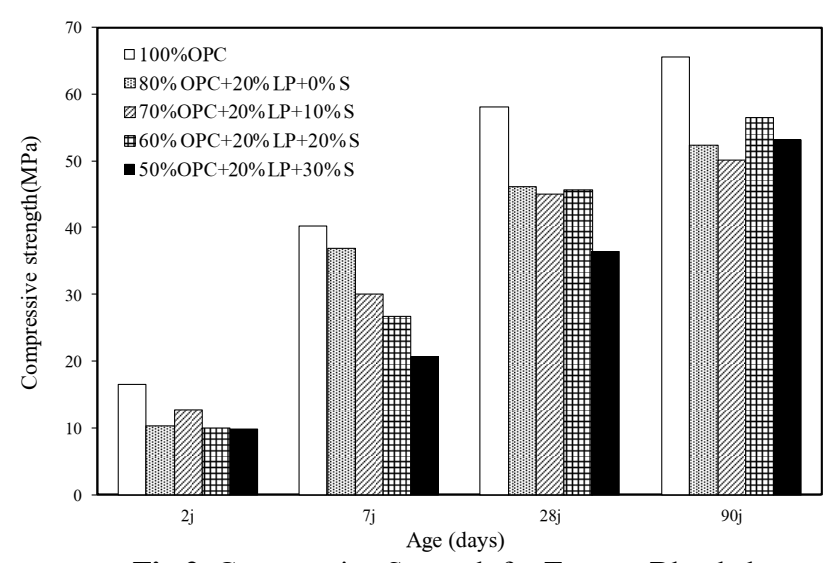

Fig.2. Compressive Strength for Ternary Blended Cement Containing Limestone Powder and Slag at Different Ages.

Fig.2 illustrates the curves of compressive strength showing the interaction effect of the LP and S for the domain studies in the ternary system. At 2, 7 and 28 days, the stationary point corresponding to the maximum compressive strength is obtained by the replacement of $20 \%$ of LP and a very little content of slag.

While, the zone of maximum strength is located around to $20 \%$ of LP, replacement is low level of slag replacement $(10 \%$ of $\mathrm{S})$. However, the values of compressive strength changes significantly at 90 days, where the maximum compressive strength is obtained with the larger proportion of Slag (20\%) and around $20 \%$ of LP. At this point the strength was $6 \%$ higher than the corresponding witness cement $(80 \% \mathrm{OPC}+20 \% \mathrm{LP}+0 \% \mathrm{~S})$. In summary, the point of maximum strength is around $20 \%$ of LP and low S replacement level at the early ages (2,7 and 28 days), after 28 days, this point moves toward the high level of $\mathrm{S}$ replacement and low LF content.

\subsection{Durability tests}

\subsubsection{Sulfate attack}

The results obtained indicate that specimen expansion increases steadily as a function of immersion time. This results in the appearance of expansive mineralogical phases in the hardened material (gypsum and secondary ettringite) which can swell and crack the cement paste. 
The quality of gypsum formed in the reaction between sulfates and portlandite $\left(\mathrm{Ca}(\mathrm{OH})_{2}\right)$, which is responsible for the formation of secondary ettringite, be further, the pozzolanic reaction produces a secondary CHS gel that also since it is deposited in the pores and enhances the paste-aggregate interface[18.19.20]. As soon as the needle crystals have no room for growth in the pores, crystallization pressure occurs, causing the expansion and ultimately the bursting of the concrete surface.

Fig.3 shows the expansion values at 6 months of exposure to $\mathrm{MgSO}_{4}$ Solution are $1.24 \%, 1.14 \%$ and 0.98 , for mixes with $0 \%, 10 \%, 20 \%$, and $30 \% \mathrm{~S}$ and $20 \% \mathrm{LF}$. The addition of $20 \%$ to $30 \%$ of Slag produces an important reduction of expansion $22 \%$ to $27 \%$ respectively than the corresponding expansion of the (OPC) mortar. These results were similar to the results obtained by Allahvedi et al [18], where they found that alkali-activated slag cement exhibits a higher sulfate resistance compared to Portland cement. It has been found that the resistance the cements to attack by sulfate never depends on the mechanical strength.

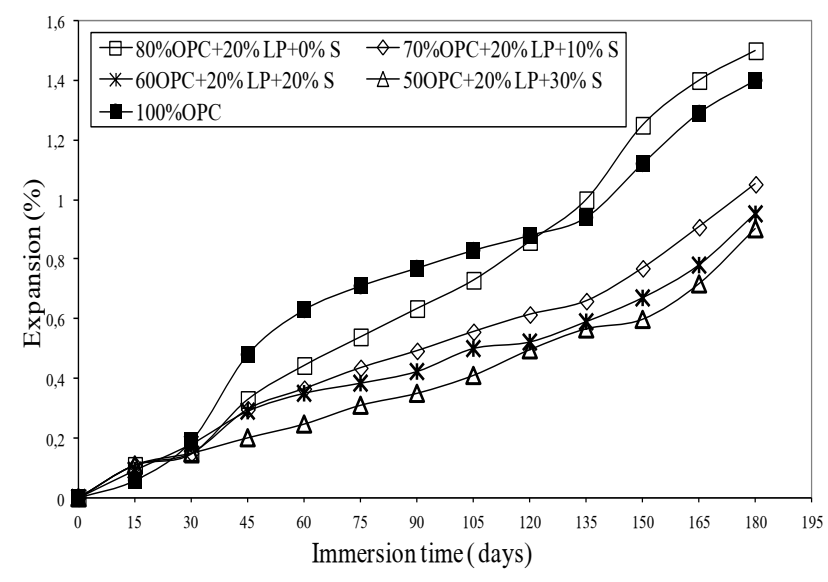

Fig.3. Expansion of mortar exposed to $5 \% \mathrm{MgSO}_{4}$

\subsubsection{Acid attack}

Fig. 4 shows the results of mass change for specimens exposed to $3 \% \mathrm{H}_{2} \mathrm{SO}_{4}$ solution for 6 months.

From these results, we observe, after 180 days exposure, the total loss in weight of mortar containing $(50 \% \mathrm{OPC}+20 \% \mathrm{LF}+20 \% \mathrm{~S})$ and mortar containing $(50 \% \mathrm{OPC}+20 \% \mathrm{LF}+30 \% \mathrm{~S})$ is lower than the ordinary Portland cement (OPC) by $20 \%$ and $23 \%$ respectively. From these results, it is noted the beneficial effect of the incorporation of slag in the cement containing the limestone powder, which minimizes the penetration of aggressive agents. So we can conclude that the incorporation $20 \%$ to $30 \%$ of slag to cement containing $20 \%$ of limestone powder have stood the acid attacks. The positive influence of the percentage of slag on the chemical resistance is translated on the one hand, by the Pozzolanic reaction which sets the portlandite released during cement hydration to form additional CSH gels of 2nd generation and therefore the compactness of carbohydrates increased, resulting in a reduction of porosity which prevents the penetration of solutions of acids in the cementitious matrix. These results are in conformity with those reported by [21].

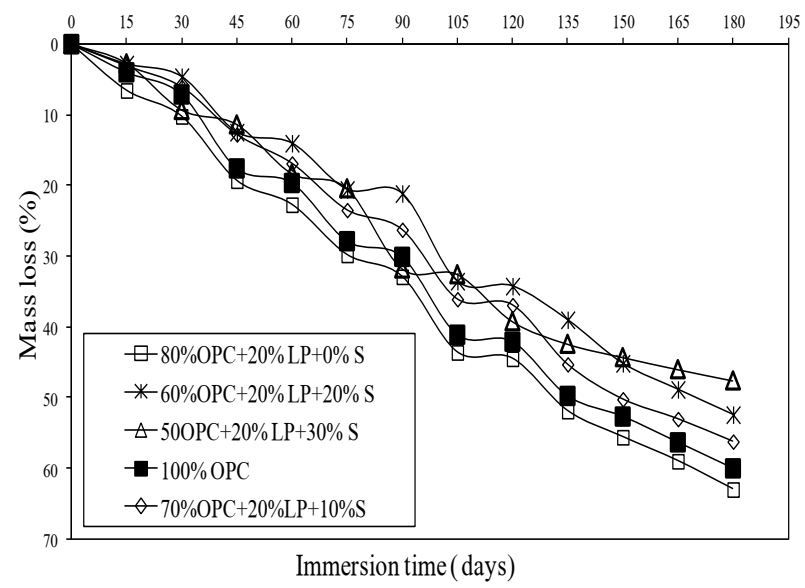

Fig.4. Weight loss of mortar due to the acid attack to $3 \%$ $\mathrm{H}_{2} \mathrm{SO}_{4}$

\section{CONCLUSION}

This study was conducted to assess the effect of the interaction between limestone powder and slag on the properties of mortar. The following conclusion can be drawn:

- The hydration heat of cement blended decreases with increases the percentage of slag in the cement containing limestone powder.

- The combination of limestone powder and slag is complementary: the point of maximum strength is around $20 \%$ of limestone powder and $20 \%$ of slag replacement level at the early ages after days, this point toward the high level of slag replacement.

- Lower expansion as observed in cement control (OPC). On the other hand slag improved the resistance to sulfate attack or the addition of $20 \%$ to $30 \%$ of slag produces an important reduction.

- It can be concluded from these results that slag addition can be used to improve sulfuric acid $\left(\mathrm{H}_{2} \mathrm{SO}_{4}\right)$ resistance.

- The use of limestone powder in the hydrochloric acid environment seems to be not recommended.

- The incorporation of the slag as addition in cement containing limestone powder is very beneficial to the resistance in sulphuric acid

- The durability performance of the cements never depends on the mechanical strength.

\section{References}

1. S. Adu-Amankwah, L. Black, J. Skocek, M. Ben Haha, M. Zajac, Constr. Build. Mater., 164, 451 (2018). 
2. CC. Castellano, VL. Bonavetti, HA. Donza, Constr. Build. Mater., 111, 679 (2016).

3. A. Bougara, K. Ezziane, A. Kadri, Canadian J. Civil Eng., 28, 555 (2010)

4. G. Menédez, V. Bonavetti, E.F. Irassar, Cem. Concr. Compos., 25, 61 (2003).

5. B. Samet, M. Chaabouni, Cement, Cem. Concr. Res. 34, 1153 (2004).

6. S.J. Barnett, M.A. Halliwell, N.J. Crammond, C.D. Adam, A.R.W. Jackson, Cem.. Concr. Compos. 24, 339 (2002).

7. PW. Brown, RD. Hooton, BA. Clark, Cem. Concr. Compos., 25, 939 (2003).

8. A.C.I. Committee, ACI Mater Journal, 92, 321, (1995).

9. SK. Rao, P. Sravana, TC. Rao, Constr. Build. Materials, 114, 925, (2016).

10. EN 196-6. Standard methods of testing cement. Part 6: Determination of fineness, (2012).

11. EN 196-9. Methods of testing cement - Part 9: Heat of hydration - Semi-adiabatic method, (2010).
12. ASTM C305-06. Standard practice for mechanical mixing of hydraulic. ASTM Int., (2006).

13. NF EN 196-1. Methods of testing cement. Deter Strength, (1996).

14. ASTM-C267-97, ASTM International, West Conshohocken, PA, (2001).

15. B. Lothenbach, G. Le Saout, E. Gallucci, K. Scrivener, Cem. Concr. Res., 38, 848 (2008).

16. P. Chaignat, F. Winnefeld, B. Lothenbach, Constr. Build. Materials, 26,619 (2012).

17. Y. Peiyu, M. Guidong, W. Qiang, J. Therm. Anal. Calorim, 115, 193 (2014).

18. A. Allahvedi, H. Hashemi, Int. J. Civil Eng., 13, 380 (2015).

19. T. Vuk, R. Gabrovesk, V. Kaucic, Cem. Concr. Res., 32, 943, (2002).

20. L. Turanli, B. Uzal, F. Bektas, Cem. Concr. Res., 35, 1106 (2005).

21. A. Aghaeipour, M. Madhkhan, Constr. Build. Materials, 141, 533 (2017). 